\title{
Shigella de adultos com disenteria aguda em Tucurui - Pará
}

\author{
Jurandir Chaves de Vasconcelos $\left({ }^{2}\right)$
}

Resumo

De 10 adultos, na faixa etária igual ou superior a 18 anos, com disenteria aguda, foram examinadas as suas fezes para pesquisa de bactérias enteropatogênicas e parasitas intestinais. As amostras foram analisadas, antes de qualquer tratamento médico, em 2 (dois) hospitais de Tucurui-PA. Em 9 (nove) casos $(90 \%)$ foram identificados os agentes etiológicos como sendo: Shigella dysenteriae -2 em 3 (três) casos e Shigella flexneri $1-6$ em 6 (seis) casos. Todas as cepas de Shigella isoladas apresentaram resistência múltipla frente às 12 drogas antimicrobianas utilizadas no estudo. Os parasitas intestinais identificados foram os seguintes: Ancilostoma sp. $70 \%$, Trichocephalus trichiurus, $60 \%$ e Ascaris lumbricoides $50 \%$.

\section{INTRODUÇÃo}

Ao fazer uma retrospectiva dos trabalhos realizados no Brasil, relacionados com a determinação da etiologia bacteriana das diarréias em adultos e crianças, concordamos com Montelli \& Trabulsi (1970) quando afirmaram ser sua maioria proveniente de capitais de estados, como: Porto Alegre (Budiansky, 1950); Curitiba (Mikoszewska, 1960); Fortaleza (Rougnayrol, 1962); São Paulo (Serrano \& Trabulsi, 1966); Manaus (Giugliano et al., 1977); São Paulo (Pessoa et al., 1978).

Montelli \& Trabulsi, (1970) estudaram as diarréias causadas por bactérias enteropato. gênicas em adultos e crianças, na cidade de Botucatu, São Paulo. Trabalho desenvolvido na localidade de Tucuruí-Pará (1981) evidenciou a incidência de bactérias enteropatogênicas de diarréia infantil aguda e a sua atuação frente a drogas antimicrobianas.

O objetivo principal deste trabaiho é, portanto, mostrar os agentes etiológicos dos qua- dros diarréicos agudos, em adultos e a sua susceptibilidade a drogas naquela lucalidade da Amazônia (Tucuruí), durante o período em que lá estivemos.

\section{MATERIAL E MÉTODOS}

Assim como o nosso trabalho anterior (1981), os estudos preliminares deste trabalho foram desenvolvidos no período compreendido entre julho e setembro de 1980, em dois hospitais em Tucuruí-Pará: Hospital da Vila temporária (Construtora Camargo Corrêa) e Hospital da SESPA (Secretaria de Estado de Saúde do Pará em Tucuruí) e, posteriormente, no laboratório de Bacteriologia do INPA.

Dez adultos com episódios de disenteria aguda foram atendidos clinicamente e coletadas as suas fezes, nos próprios hospitais, antes de qualquer tratamento médico.

\section{COLETA DE AMOSTRAS}

As amostras fecais foram coletadas em frascos plásticos de boca larga e logo em seguida processadas para os exames (parasitológico e bacteriológico).

\section{EXAME BACTERIOLÓGICO DAS FEZES}

Logo após a coleta, as fezes foram semeadas em MacConkey Agar, Salmonella - Shigella-Agar (SS Agar), Hektoen Enteric Agar e Tetrathionate Broth. As colônias bacterianas com características de Escherichia coli, Salmonella e Shigella foram conservadas em Agar nutriente e estocadas para a sua identificação

(1) - Este trabalho foi realizado com o apoio do Conse lho Nacional de Desenvolvimento Científico e Tecnológico (CNPq) através de convênio entre o Instituto Nacional de Pesquisas da Amazônia (INPA) e a ELETRONORTE, no PROJETO TUCURUÍ.

(2) - Instituto Nacional de Pesquisas da Amazônia, Manaus. 
posterior. Os métodos de identificação bioquímica e sorológica dos germes isolados foram os recomendados por (Edwards \& Ewing, 1975) e efetuados no Laboratório de Bacteriologia do INPA. A sorologia foi efetuada com soros da DIFCO Laboratories e do Instituto Adolfo Lutz, São Paulo,

\section{EXAME PARASITOLÓGICO DAS FEZES}

As amostras de fezes foram examinadas para estudo parasitoiógico através do método direto com e sem lugol, para evidenciação de formas císticas e trofozoíticas de protozoários e ovos e larvas de helmintos (Pessoa, 1972).

TESTE DE SUSCEPTIBILIDADE A DROGAS

As bactérias enteropatogênicas isoladas foram submetidas ao teste de susceptibilidade a drogas pelo método do disco, descrito por Bauer et al. (1966). Foram utilizadas as seguintes drogas: Ampicilina (10 mcg), Ac. Nalidixo $(30 \mathrm{mcg})$, Canamicina $(30 \mathrm{mcg})$, Carbenicilina $(100 \mathrm{mcg})$, Cloranfenicol $(30 \mathrm{mcg})$, Estreptomicina $(10 \mathrm{mcg})$, Gentamicina $(10 \mathrm{mcg})$, Neomicina $(30 \mathrm{mcg})$, Nitrofurantoína (300 U.), Novobiocina (30 mcg), Polimixina (300 U.) e Tetraciclina $(30 \mathrm{mcg})$. Todas as drogas utilizadas eram provenientes da Sensibiodisc CECON (São Paulo, Brasil).

\section{Resultados}

Dez adultos na faixa etária igual ou superior a 18 anos, com quadro clínico de disente. ria aguda, foram atendidos em dois hospitais de Tucuruí. As amostras fecais foram examinadas para estudos bacteriológico e parasitológico.
$\mathrm{Na}$ tabela I, podemos verificar os resultados dos exames parasitológicos nos dez adultos, mostrando a mesma, os parasitas intestinais encontrados e suas respectivas porcentagens. Sendo: Ancilostoma sp 70\%, T. trichiurus, $60 \%$ e Ascaris lumbricoides, $50 \%$.

TABELA I - Parasitas intestinais encontrados nos 10 casos de disenteria, número e respectiva porcentagem de identificação.

\begin{tabular}{l|c|c}
\hline \multicolumn{1}{c|}{ Espécie } & N. & $\%$ \\
\hline Ancilostoma sp. & 07 & 70 \\
Trichocephalus trichiurus & 06 & 60 \\
Ascaris lumbricoides & 05 & 50 \\
\hline
\end{tabular}

A tabela II mostra a distribuição por sexo, se trabalhador ou não da Usina Hidrelétrica de Tucuruí, dos 10 episódios de disenteria e sua porcentagem de isolamento do agente etiológico.

Dentre os 10 casos estudados, somente em um não foi possível o isolamento do agente causador, isto dado o extravio do material em nosso laboratório no INPA; entretanto, a pessoa apresentava os mesmos sintomas daquelas que foram isoladas Shigella: febre, mal-estar e as suas fezes mucosanguinolentas.

De 7 pessoas do sexo masculino foram isoladas: - Shigella dysenteriae - 2 em um caso, enquanto Shigella flexneri $1-6$ foram isoladas de cinco casos. O outro caso foi justamente aquele em que o material foi extraviado. Das 3 pessoas do sexo feminino, foram isoladas: Shigella dysenteriae -2 , de dois casos, enquanto do outro caso foi isolada Shigella flexineri $1-6$.

Através da tabela III, verificamos o comportamento das cepas de Shigella isoladas e

TABELA II - Distribuição por sexo, traba'hador ou não da Hidrelétrica de Tucuruí, dos 10 episódios de disenteria aguda em adultos e sua porcentagem de positividade de isolamento do agente etiológico.

\begin{tabular}{|c|c|c|c|c|c|c|c|}
\hline Idade & $N^{\circ}$ de casos & $\hat{A}$ & 오 & Trabalhador & Não Trabalhador & \multicolumn{2}{|c|}{ Positividade } \\
\hline (anos) & N. de casos & 0 & & da U.H.E. & da U.H.E. & N. ${ }^{\circ}$ & $\%$ \\
\hline $18 \geqslant$ & 10 & 7 & 3 & 3 & 7 & 9 & 90 \\
\hline
\end{tabular}


TABEL.A III - Cepas de Shigella isoladas e o seu modelo de resistência a diferentes drogas antimicrobianas

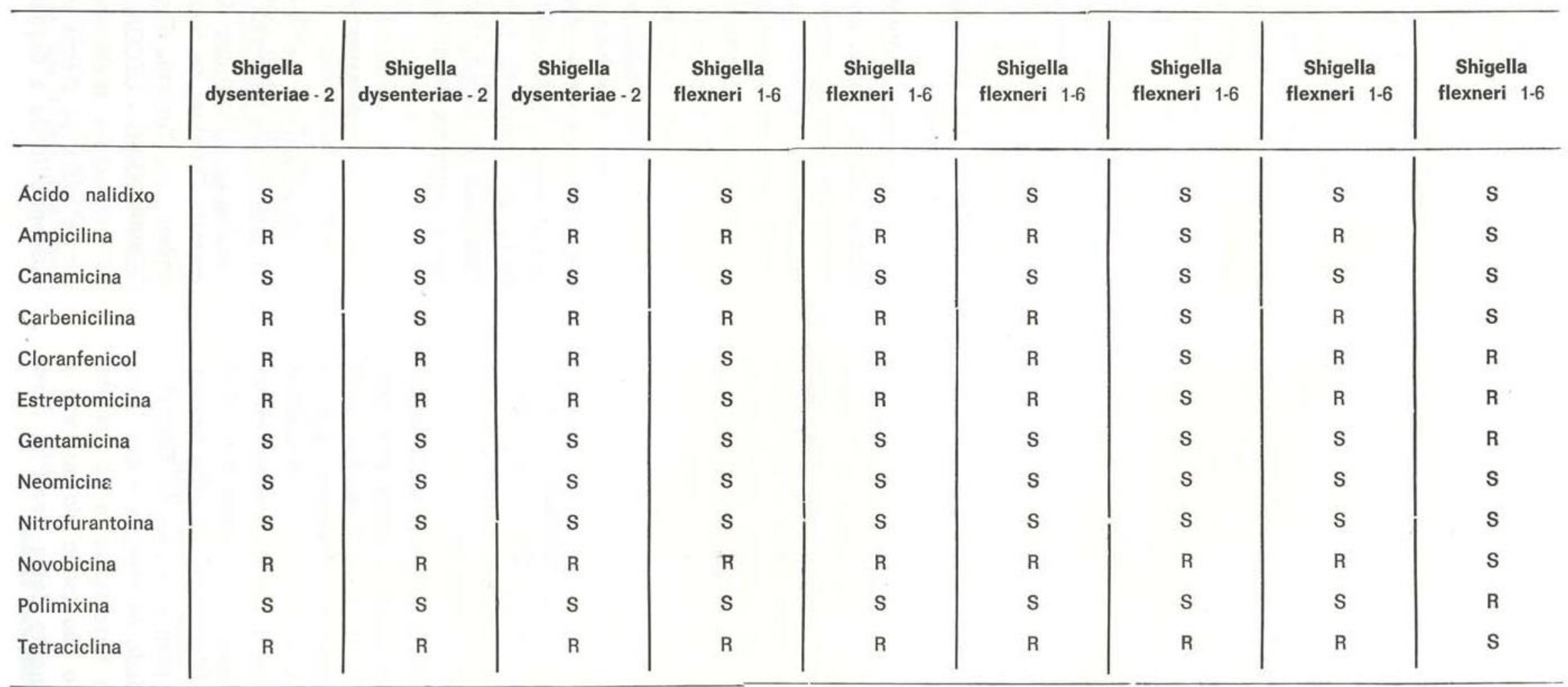


o seu modelo de resistência às 12 diferentes drogas antimicrobianas utilizadas. Observa-se que todas elas apresentaram resistência múltipla, sendo: 5 cepas (duas de $S$. dysenteriae -2 e três de $S$. flexineri $1-6$ ) foram resistentes a 6 drogas (ampicilina, Carbenicilina, Cloranfenicol, Estreptomicina, Novobiocina e Tetraciclina); 3 cepas foram resistentes a 4 drogas; uma de $S$. dysenteriae -2 foi resistente ao Cloranfericol, Estreptomicina, Novobiocina e Tetraciclina; uma de Shigella flexneri $1-6$ foi resistente a Ampicilina, Carbenicilina, Novobiocina e Tetraciclina; uma cepa de $S$. flexneri $1-6$ foi resistente a Cloranfenicol, Estreptomicina, Novobiocina e Tetraciclina; enquanto 1 cepa de Shigella flexneri 1 -6 apresentou resistência somente a duas drogas (Novobiocina e Tetraciclina).

\section{DISCUSSÃo}

É enorme o número de trabalhos realizados em que foram isolados cepas de Shigella como agente etiológico de diarréia, em adultos e crianças, no nosso meio e em outros países. Além dos já citados; Floyd et al., (1953); Fournelle et al., (1966); Gangarosa et al., (1970); Kourany \& Vasques (1969); Mata et al., (1970); Taunay et al., (1956).

Todavia, poucos são os trabalhos no Brasil que mostram o isolamento de cepas de Shigella dysenteriae - 2. Estudos desenvolvidos em São Paulo por Zuliani \& Trabulsi (1968); trabalho também efetuado em São Paulo no septênio 70-76, Pessoa et al., (1978).

$\mathrm{O}$ isolamento desta bactéria neste estudo não quer dizer que somente agora esta cepa tenha surgido naquela localidade. Por outro lado, podemos afirmar pela literatura que nos foi possível consultar, ser esta a $1 .^{\star}$ publicação em qu€ aparece o seu isolamento na região amazônica, apesar de a mesma já ter sido isolada em nosso laboratório, de uma pessoa, que havia viajado para a região do Tarumãzinho, próxima à cidade de Manaus e que havia sido acometida de forte episódio de disenteria bacilar. Mesmo não tendo ido ao local e tentado o reisolamento desta bactéria, deve- mos levar em consideração que esta pessoa era de origem alemã e havia chegado recentemente a Manaus. Daí, não sabermos se a mesma já rião havia se infectado em seu país de origem ou em outra localidade.

O baixo número de diarréia, de apenas 10 casos, não deverá significar a realidade da incidência de episódios de doenças gastrintestinais, em adultos, na localidade de Tucuruí. Este númerc simplesmente representa os casos que foram levados ao nosso conhecimento e que por isso mesmo tivemos a oportunidade de estudá-los.

Pelo fato de não ter sido isolada Salmonella neste estudo, também não se poderá afirmar a sua inexistência local, como agente etiológico de diariéia. Apesar de que em estudo anterior também não ter sido isolada esta bactéria em crianças acometidas de gastrenterite aguda.

A resistência múltipla apresentada a diferentes drogas pelas amostras isoladas, vem concordar com os resultados obtidos por outros autores, sendo que Zuliani \& Trabulsi (1968) isolaram cepas de Shigella resistentes a Sulfadiazina, Estreptomicina, Tetraciclina, Cloranfenicol, Neomicina e Hetacilina, enquanto neste estudo as cepas foram resistentes a Ampicilina, Carbenicilina, Cloranfenicol, Estreptomiciná, Novobiocina e Tetraciclina. Estes resultados vêm cada vez mais mostrar o uso abusivo e indiscriminado de drogas por parte da população, levando isto sempre às condições de cepas resistentes a essas drogas e, portanto, de mais difícil tratamento.

\section{AGRADECIMENTOS}

Expressamos os nossos agradecimentos ao pessoal dos Lahoratórios de Análises Clínicas dos dois Hospitais: Camargo Corrêa e Secretaria Estadual de Saúde do Pará (SESPA), ambos em Tucuruí. Também agradecemos a SENSIBIODISC - CECON (São Paulo) pela sua compreensão e ajuda, cedendo muito gentilmente todos os discos utilizados no teste de susceptibilidade a drogas antimicrobiznas. 


\section{SUMMARY}

Bacteriological and Parasitological studies were carried out in the faeces of 10 dysenteric adults $18 \geqslant$ years old. Samples were examined, before any medical treatment, in two hospital in Tucuruí, Pará, Brazil.

In 9 cases $(90 \%)$ the aetiological agents were identified: Shigella dysenteriae -2 in 3 cases and Shigella flexneri $1-6$ in 6 .

All Shigella strains isolated showed multiple resistance to 12 antimicrobial drugs.

The intestinal parasites identified were: Ancilostoma sp. $70 \%$, Trichocephaius trichiurus, $60 \%$ and Ascaris lumbricoides, $50 \%$.

\section{REFERENGIAS BIBLIOGRAFICAS}

BAUER, A.W.; KIRBY, W.M.M.; SHERRIS, J.C. \&

TURCK, M,

1966 - Antibiotic susceptibility testing by standardized single disk method. Am. J. Clin. Path., 45 (4): 493-496.

BUDIANSKY, E,

1950 - Contribuiçẫo ao estudo das diarreias agudas em Porto Alegre: suas relaçōes com as Shigeloses e Salmoneloses, Porto Alegre, tese Fac. Med. Porto Alegre.

EDWARDS, P.R. \& EWING, W.H.

1975 - Identification of Enterobacteriaceae $3 \mathrm{rd}$. ed. Minneapolis Minnesota, U.S.A., 362p.

FLOYD, T.M.; HIGGINS, A:R. \& KADER, M.A.

1956 - Studies in Shigellosis. V. the relationship of age to the incidence of Shigella infections in Egyptian children, with special reference to Shigellosis in the newborn and infants in the first six month of life. Am. J. Trop. Med. Hyg., 5: 119-30.

FOURNELLE, H.J.; GRACIAN, M. \& MEDINA, P.

1966 - Enfermedades diarreicas en Colombia: informe de una encuesta bacteriologica. Bol. Of. Sanit. Pan-am., 61: 408-13.

GANGAROSA, E.J.; PERERA, D.R.; MATA, L.J.;

MENDIZABAL-MORRIS, C.; GUZMAN, G. \& RELLER, L.B.

1970 - Epidemic Shiga bacillus dysentery in Central America. II. Epidemiologic studies in 1969. J. Infect. Dis., 122: 181-190.

GIUGLIANO, L.G.; GIUGLIANO, R. \& PINHEIRO, M.F.

1977 - Bacterias enteropatogênicas em lactentes de um bairro de Manaus - Amazonas. Acta Amazonica. 7 (3): 395-400.

KOURANY, M. \& VASQUEZ, M.A.

1969 - Housing and certain socioenviromental factors and prevalence of enteropathogenic bacteria among infants with diarrheal disease in Panama. Am. J. Trop. Med. Hyg., 18: $936-941$.
MATA, L.J.; GANGAROSA, E.J.; CÁCERES, A.; PERERA, D.R. \& MEJICANOS, M.L.

1970 - Epidemic Shiga bacillus dysentery in Central America. 1. Entiologic investigations in Guatemala. J. Infect. Dis., 122: 170-180.

MOKOSZEWSKA, I.

1960 - Shigelose em crianças de Curitiba. An. Fac. Med. Curitiba. 3: 38 .

MONTELLI, A.C. \& TRABULSI, L.R.

1970 - Diarréias causadas por "Shigella", "Salmonella" e "E. coli" enteropatogênica no Município de Botucatu, São Paulo. Rev. Ass. Med. Bras., 16: 23-26.

PESSOA, S.B.

1972 - Parasitologia Médica. Guanabara Koogan.

PESSOA, G.V.A.; CALZADA, C.T.; PEIXOTO, E.S.;

MELLES, C.E.A.; KANO, E.; RASKIN, M.; SIMONSEN, V.: IRINO, K.

1978 - Ocorrências de Bacterias enteropatogênicas em São Paulo no septênio 1970-76. III - Sorotipos de Shigella e de Escherichia coli da gastrenterite infantil. Rev. Inst. Adolfo Lutz, 38 (2): 129-139.

ROUQUAYROL, M.Z.

1962 - Diarréias infantis em Fortaleza: contribu، ção ao estudo, com especial referência às Shigeloses S.L.P., Tese, Fc. Farm. \& Odont. Univ. Ceará.

SERRANO, J.A. \& TRABULSI, L.R.

1966 - Observações sobre a frequeência de isola. mento de Shigella, Salmonella e E. coli enteropatogênica das fezes de crianças com diarréia aguda na cidade de São Paulo. Arq. Gastroent., 3: 221.

TAUNAY, A.E.; PONTES, J.F.; PRADO, E. \& PEIXOTO, E.S. 1956 - Shigeloses. Comparação de métodos de colheita das fezes no diagnóstico bacteriológico das enterocolites crônicas. Aglutininas e coproaglutininas na enterocolite crônica. Rev. Inst. Adolfo Lutz, 16: 37-61.

VASCONCELOS, J.C.

1981 - Bacterias Enteropatogênicas de Diarréia Infantil Aguda em Tucuruí-Pará. Acta Amazonica, 11 (3): 527-535.

ZULIANI, M.E. \& TRABULSI, L.R.

1968 - Sensibilidade in vitro à sulfadiazina e a 5 antibiótico de 166 amostras de Shigella, isoladas em S. Paulo, Brasil. Rev. Inst. Med. Trop. S. Paulo, 10: 70-77.

(Aceito para publicação em 11/02/82) 